\title{
GROUNDED THEORY METHODOLOGY IN THE CONTEXT OF SOCIAL INNOVATIONS FOR RURAL DEVELOPMENT RESEARCH
}

\begin{abstract}
Rasa PRANSKŪNIENĖ, Business and Rural Development Management Institute, Aleksandras Stulginskis University, Universiteto g. 10, LT-53361, Akademija, Kauno raj. Lithuania, rasa.pranskuniene@ asu.lt

Although the Grounded Theory (GT) methodology has been developed for over 50 years and is one of the most popular methodologies in the world, it is not often used in rural development research. In order to update the possibilities of applying GT in rural development research, this article is based on the analysis of scientific literature and presents the evolution of the development of GT methodology and the possibilities of its application in rural development research. The classic GT strategy is discussed in more detail, as methodology which provides the possibility to researcher to look at the phenomenon from inside without formulating the hypothesis, i.e., to "emerge" the theory, which reveals the main concern and explains how it is resolved, by conceptualizing the authentic experiences of research participants. The article aims to explain that classic GT is a "full package" approach, discusses its coding process; reveales the principles of the emerging classic GT. The GT methodology is discussed as the paradigm that can help researchers discover new insights and develop new theories, explaining the processes of social innovations for rural development.
\end{abstract}

Keywords: grounded theory, social innovation, rural development

\section{INTRODUCTION}

Although in today's dynamic, full of changes world, social innovations are highlighted, but in rural areas, social innovations do not evolve as rapidly and as effectively, as it is expected. Although the Grounded Theory (GT) methodology has been developed for over 50 years and is one of the most popular methodologies in the world, it is not often used in rural development research. According to Melece (2015), the growth of modern economic systems has generated more numerous, complex and urgent social challenges. And as Konstantos et al. (2013) indicate, socially innovative initiatives are developed in reaction to increasing inequalities as well as to processes of social exclusion, mobilizing different resources. In this regard, understanding such phenomena requires specific methodologies to approach and learn along with the actors, objectives and practices comprised.

It is important to note, that more and more variuos studies, such as a life history methodology (Ross, 2014), critical discourse analysis (Takala et al., 2017), ethnographic discourse analysis (Christmann, 2016), phenomenological analysis (Hennon, 2012; Joshi, 2015) and others occur. According to Takala et al. (2017) our understanding of the world is essentially based on shared meanings that are intersubjectively produced and reproduced in different social practices. It is also perceived by Galliano et al. (2017), that it is important to increase knowledge concerning the dynamics of innovation in rural areas. Bock (2016, as cited in Copus et al. 2017) notices that the political-economic context of rural development has changed and conceptually social innovation transcends the boundaries of specific places and even the rural space, it becomes evident that rural social innovation requires networking and the building of relations across the borders of the place in question. According to Carrero et al. (2000), who studied radical organizational innovation through grounded theory, pointed out the importance of the focus from this perspective is on understanding the development of innovation by using flexible and open research designs that allow us to reflect on the frequent changes and inner movements that characterize the organizational context; this emerging paradigm often involves theory-building approaches that lead to the discovery of relevant social processes during the development of innovations.

This article is based on the analysis of scientific literature in order to update the possibilities of applying GT in the context of social innovations for rural development research. As GT methodology is unique methodology and isn't very common in rural development research area, it is important to discuss it more deeply. So the article seeks to reveal the evolution of the development of GT methodology, presents classic GT strategy and discusses GT methodology as the paradigm that can help researchers to discover new insights and develop new theories, explaining the processes of social innovations for rural development.

Copyright (C) 2017 The Authors. Published by Aleksandras Stulginskis University. This is an open-access article distributed under the terms of the Creative Commons Attribution License (CC-BY 4.0), which permits unrestricted use, distribution, and reproduction in any medium, provided the original author and source are credited. 


\section{THE EVOLUTION OF THE DEVELOPMENT OF GT METHODOLOGY}

It is important to mention, that social innovations and rural development are understood here as the context and area where could be used GT methodology. According to that - as GT methodology is very unique methodology and not very common in rural development research area, it seemed important to discuss it more deeply.

Origins of GT. According to Bryant (2017), the GT itself first came to researchers' attention in the 1960s, when Barney Glaser and Anselm Strauss published their initial detailed grounded theory study Awareness of Dying (1965), soon followed by the more generic, methods-oriented book The Discovery of Grounded Theory (1967). As Bryant (2017) notices, they supplemented this with a further, related study Time for Dying (1968). These three volumes have come to be seen as the core texts for the method and are referred to throughout this book in abbreviated form as the trilogy, Awareness, Discovery, and Time (Bryant, 2017).

What made The Discovery of Grounded Theory (Glaser and Strauss, 1967) innovative in 1967? Bryant and Charmaz (2010) noticed that at the time it was not only highly innovative, but a direct challenge to the prevailing orthodoxies, methodologies and research protocols of American social science research. These authors pointed out, that Glaser and Strauss argued that the researcher could and even should dispense with the formulation of a preliminary hypothesis. Kenny and Fourie (2014) pointed out, that Glaser and Strauss designed a number of distinct methodological techniques unique to GT; they stipulated that data collection and analysis occur simultaneously and should be conducted through the specific procedures of theoretical sampling, coding, constant comparison, saturation and memo writing. Glaser and Strauss designed these exacting techniques to ensure that as data is collected, coded, compared, and organised into increasingly abstract categories, a budding theory will begin to emerge (Kenny and Fourie, 2014).

Rupsiene and Pranskuniene (2010) pointed out, that in their book Glaser and Strauss (1967) argued that the generation of theory from empirical data is of the same importance as theory verification; they attempted to convince researchers that each researcher, not only geniuses, can generate their own theories. Their contribution to research methodology was described by Simmons (2010, p. 15) even as "democratic option into the social sciences that enabled anyone who learned the methodology to generate theory".

Split of GT. Kenny and Fourie (2014) noticed, that in the 1970's and 80's Glaser and Strauss each wrote a further exposition of GT, but published their books separately rather than collaboratively (Glaser, 1978; Strauss, 1987). Therefore, Arora (2016) pointed out, that the Straussian tradition of grounded theory began due to their disagreement on the nature of the method and how it is supposed to be applied. By the 1990's Strauss had forged an academic alliance with Corbin, and together they revised the original grounded theory into a more prescriptive, detailed method that contained step-by-step guides to its process.

According to Bryant (2017) in the 1990s the method continued to evolve in other ways, most notably with the development of what has been termed Constructivist grounded theory, introduced and articulated in the work of Kathy Charmaz, most notably in Constructing Grounded Theory (2006, 2014). According to Charmaz, "neither the data nor the theories are discovered" and "we construct our grounded theories through our past and present involvements and interactions with people, perspectives and research practices" (Charmaz, 2006, p. 10).

The variety of GT. According to Goulding (2017), today it is generally accepted that there are at least three and possibly up to five versions of grounded theory, each with its own distinct ontological foundations. As such, it is expected and indeed incumbent on the researcher to make clear which version of grounded theory was used, why it was used, and how it was used. The three main versions most commonly adopted can broadly be identified as classic grounded theory, associated with Barney Glaser; evolved grounded theory, which is essentially the product of Strauss and Corbin's (1990) revision of the original methodology; and Charmaz's $(1983,2005,2008)$ constructivist grounded theory (ChamberlainSalaun, Mills, and Usher 2013, as cited in Goulding, 2017).

According to Rupsiene and Pranskuniene (2010), one more unique approach was propagated by the first graduate of Strauss - Leonard Schatzman, who presented dimensional analysis "as a methodological approach to the grounding theory in qualitative research" in 1991 (Schatzman, 1991, p. 303); one more approach towards GT is propagated in the works by Adele Clarke (2005). Her attitude is based on postmodernism; it is also possible to notice that there are more GTs: e.g., Goldkuhl and Lind (2006) propose Multi GT (MGT) version, which is presented as a dialectical synthesis between inductivism and deductivism. These versions are variously classified by different theorists (Bryant, 2003; Creswell, 2005; Babchuk, 2009; Muller, 2010 (fig. 1), as cited in Rupsiene, Pranskuniene, 2010). Holton (2007) noticed, that various scholars have positioned grounded theory as positivist (Charmaz, 2000), constructivist (Charmaz, 2000), interpretivist (Lowenberg, 1993), pragmatist (Locke, 2001), realist (Lomborg, Kirkevold, 2003; Partington, 2000, 2002; Patton, 2002), and neo-empiricist (Johnson et al., 2006). Rupsiene and Pranskuniene (2010) pointed out, that Denzin (2007) differentiates even seven GT versions: positivist, post-positivist, constructivist, objectivist, postmodern, situational and computerized. It is also perceived by Goulding (2017) a more recent but less established addition is transformational grounded theory (Redman-MacLaren, Mills 2015); therefore Konecki (2011) advocates what he calls "visual grounded theory" and points in particular to the work of Adele Clarke (2005).

Tikhonravova (2017) noticed, that Bryant does not prioritize one method of GT over others; rather, he speaks about grounded theory method as a family of methods, which includes: "pure" GT (Glaser, 1992); coding paradigm (Corbin, Strauss, 2015; Strauss, Corbin, 1990); the constructivist approach (Charmaz, 2006, 2014); and the pragmatist approach described by the author. According to Breckenbridge (2010) despite being widely used, particularly within qualitative healthcare literature, most "grounded theory" studies reveal little of the complex debates surrounding the 
progressive division of the methodology into three main "strands": Classic (or Glaserian) grounded theory, Straussian grounded theory and Constructivist grounded theory.

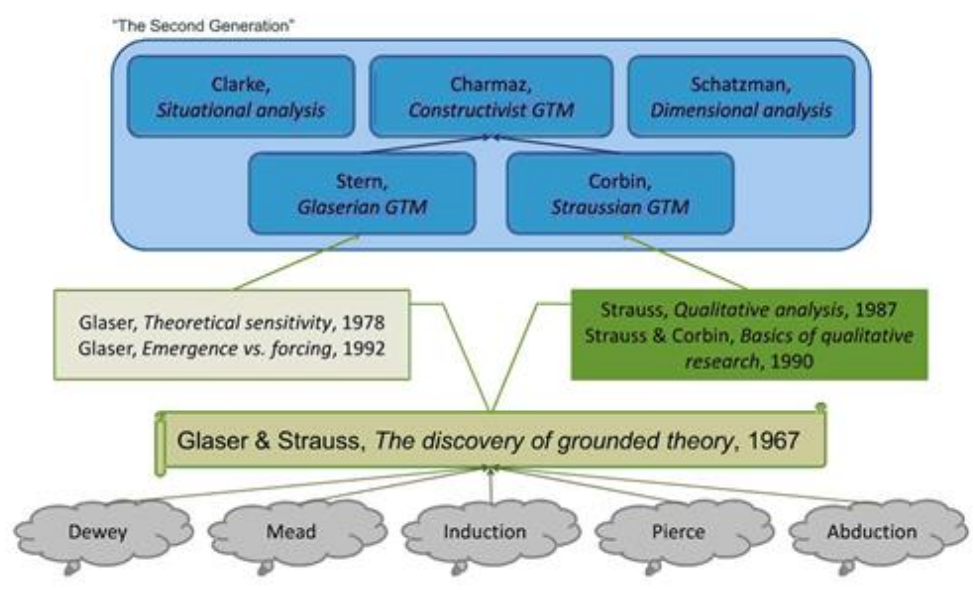

Figure 1. The classification of grounded theory (Muller, 2010)

\section{THE CLASSIC GT STRATEGY}

The classic GT strategy is discussed in more detail, as methodology which provides the possibility to researcher to look at the phenomenon from inside without formulating the hypothesis, i.e., to "emerge" the theory, which reveals the main concern and explains how it is resolved, by conceptualizing the authentic experiences of research participants. The article aims to explain that classic GT is a "full package" approach, discusses its coding process; reveales the principles of the emerging classic GT. Glaser (1992, p.16) states, that GT is "a general methodology of analysis linked with data collection that uses a systematically applied set of methods to generate an inductive theory about a substantive area". GT it is an act of conceptual abstraction (Holton, 2007; Holton, Walsh, 2016), it is this ability, as Holton (2007) argues, to abstract from empirical indicators (incidents in the data under analysis) the conceptual idea without the burden of descriptive detail that distinguishes the coding process in classic grounded theory methodology. For a classic grounded theorist, what matter are the concepts. Holton (as cited in Walsh et al., 2015) notices that classic GT is ontologically and epistemologically flexible. According to Breckenridge (2010), classic GT aims to identify a pattern of behaviour that transcends empirical difference in order to provide a conceptual, rather than descriptive or interpretive, rendering of participant behaviour.

As can be dealt from the works of Glaser (1967, 1978, 1992, 2009, 2010 et al.) and his followers (Holton, 2007, 2009; 2017; Scott, 2007, 2017; Breckenridge, 2009, 2010; Christiansen, 2017; Walsh et al., 2015 and others), the specifics of the classic GT is presented in several aspects and the most important principles of classic GT are discussed in more detail.

"Full package". The decision to use classic GT methodology is the "full package" decision (Holton, 2007). It requires the adoption of a systematic set of precise procedures for collection, analysis and articulation of conceptually abstract theory. Holton (as cited in Walsh et al., 2015) points out, that the full package of GT can be applied to any data, and the full package must be applied to merit the distinction of a GT; GT is its own paradigm - a practice paradigm of emergent theory generation as discovered in empirical data.

Holton (2007) points out, that the decision to use classic GT methodology is a "full package" decision. It requires the adoption of a systematic set of precise procedures for collection, analysis and articulation of conceptually abstract theory. Holton (as cited in Walsh et al., 2015) points out, that the full package of GT can be applied to any data, and the full package must be applied to merit the distinction of a GT; GT is its own paradigm - a practice paradigm of emergent theory generation as discovered in empirical data.

"All is data". With Glaser's often quoted dictum, "All is data" and its goal of conceptual abstraction, classic GT methodology uses data of all types and media and accommodates a range of epistemological and ontological perspectives without having to espouse any one perspective; in essence, the methodology is epistemologically and ontologically neutral (Holton, 2007), so as Collins (2011) points out, GT may include various philosophical perspectives, but the key point is that each perspective needs to earn its way into the particular theory on the same basis as any other part of the theory. GT "can be used on any data or combination of data" (Glaser, 2010, p. 9). Glaser (1978) reminds, that classic GT can use either qualitative or quantitative data as it is a general methodology.

Coding. According to Holton (2007) coding is the core process in classic GT methodology. There are two types of coding in a classic GT study: substantive coding, which includes both open and selective coding procedures, and theoretical coding. In substantive coding, as Holton $(2007,2010)$ noticed, the researcher works with the data directly, fracturing and analysing it, initially through open coding for the emergence of a core category and related concepts and then subsequently through theoretical sampling and selective coding of data to theoretically saturate the core and related 
concepts. Hernandez (2009) notes, that first, during the open coding process, the data are broken down into substantive codes as interview, field notes and/or other written data are coded in a line by line manner and incidents are compared with one another, for similarities and differences (Glaser, 1978) until the core category is found. Theoretical codes conceptualize how the substantive codes may relate to each other as hypotheses to be integrated into the theory. Holton (2007) notices, that the coding process is not a discrete stage as it is in some research methodologies but rather a continuous aspect of the analytic nature of classic GT.

Constant comparison of the data. The constant comparative process continues (Glaser, Holton, 2004, Holton, 2007) through open coding to selective coding and involves three types of comparison: first, incidents are compared to other incidents to establish the underlying uniformity and varying conditions of generated concepts and hypotheses; then, emerging concepts are compared to more incidents to generate new theoretical properties of the concepts and more hypotheses. The purpose here is theoretical elaboration, saturation, and densification of concepts; finally, emergent concepts are compared to each other with the purpose of establishing the best fit between potential concepts and a set of indicators, the conceptual levels between concepts that refer to the same set of indicators and their integration (theoretical coding) into hypotheses to become theory (Glaser, Holton, 2004). According to Holton (2007), the purpose of constant comparison is to see if the data support and continue to support emerging categories. At the same time, the process further builds and substantiates the emerging categories by defining their properties and dimensions. Constant comparison resolves "data overwhelm" (Glaser, 2003, p. 24, as cited in Holton, 2007).

Theoretical sampling is described as "the process of data collection for generating theory whereby the analyst jointly collects, codes and analyses his data and decides what data to collect next and where to find them, in order to develop his theory as it merges" (Glaser and Strauss, 1967, p. 45). According to Breckenridge (2009) theoretical sampling is a central tenet of classic GT and is essential to the development and refinement of a theory that is "grounded" in data. Glaser and Holton (2004, p.10) state that "only as the researcher discovers codes and tries to saturate them by theoretical sampling in comparison groups, do the successive requirements for data collection emerge - both (1) what categories and their properties to be sampled further and (2) where to collect the data".

Theoretical sensitivity is one of the most important elements of GT. It was described in the first book (Strauss, 1967, p.46) of GT co-originators as "an ability to have theoretical insight into \{one's \} area of research, combined with an ability to make something of \{one's\} insights". According to Glaser and Holton (2004, p. 8), a researcher needs two essential characteristics in order to achieve theoretical sensitivity: "First, he or she must have the personal and temperamental bent to maintain analytic distance, tolerate confusion and regression while remaining open, trusting to preconscious processing and to conceptual emergence. Second, he/she must have the ability to develop theoretical insight into the area of research combined with the ability to make something of these insights. He/she must have the ability to conceptualize and organize, make abstract connections, visualize and think multivariately". Therefore, the first step to reach theoretical sensitivity is to enter the research field having as little preconceived ideas as possible, without any preconceived, especially logically deducted, prior hypotheses. Hernandez (2009) emphasizes, that the researcher's theoretical sensitivity enhances his or her ability to recognize the theoretical codes as they emerge during coding and memoing.

Threoretical saturation. As argued by Holton (2007), theoretical saturation is achieved through constant comparison of incidents (indicators) in the data to elicit the properties and dimensions of each category (code). "Once a category is saturated it is not necessary to theoretically sample anymore to collect data for incident comparisons. And of course, once many interrelated categories of a GT are saturated, theoretical completeness is achieved for the particular research" (Glaser, 2001, p. 192). Holton (2007) reminds us, that one stops when one no longer needs to continue.

The usage of literature. Glaser $(1992$, p. 31) states that "here is a need not to review any of the literature in the substantive area under study". However, he does not reject the usage of literature in general: "when the grounded theory is nearly completed during sorting and writing up, then the literature search in the substantive area can be accomplished and woven into the theory as more data for constant comparison" (Glaser, 1998, p.67). He points out, that the preconceived literature review is a waste of time and a derailing of relevance for the GT study. What is more, according to them, to undertake an extensive review of literature before the emergence of a core category violates the basic premise of GT; that being, the theory emerges from the data not from extant theory.

Memoing. According to the explanation of Glaser, as Holton (2004) points out, memos are theoretical notes about the data and the conceptual connections between categories. Holton (2007) notices, that memoing occurs initially at the substantive coding level and proceeds to higher levels of conceptual abstraction as coding proceeds to theoretical saturation and the theorist begins to explore conceptual reintegration through theoretical coding. It is also perceived by Hernandez (2009), that writing memos will force researchers to theoretically code (Glaser, 1978, p. 85) to determine how a particular category is related to other categories that have been discovered already. Glaser (1978, p. 84) explains: "memos serve as a means of revealing and relating by theoretically coding the properties of the substantive codes".

Sorting. This is one of the last procedures applied in the process of generation of GT; it requires patience and attention from a researcher because this procedure is usually time consuming. Glaser (1978) emphasises that the sorting is a necessary step in GT, which cannot be missed. During the sorting, the most important is to carry out theoretical sorting of memoing while preparing for the writing stage. Thus, the sorting proceeds at the same time as the theory writing. Glaser (1978) notes that actually the ideas are being sorted, not data, because this is a conceptual sorting. Thus, the sorting generates the complex theory. Moreover, the sorting integrates literature into the theory which is being sorted together with the memoing. Sorting prevents over-conceptualization and pre-conceptualization, since these excesses fall away as the researcher zeros in on the most parsimonious set of integrated concepts (Glaser, Holton, 2004). During sorting, Hernandez (2009) notices, the researcher places each memo onto the pile to which it belongs, based on the substantive code (s) to which it refers. 
Writing. Glaser (2009) reminds us, that the dictum is to write conceptually, by making theoretical statements about the relationship between concepts. The most important thing to remember is to write about concepts, not people. Thus, the analyst writes in such a way as to make explicit the dimensions, properties or other theoretical codes of his theory as well as the theoretical integration of these codes. Glaser (2009) notices, that saying this is easier than doing it!

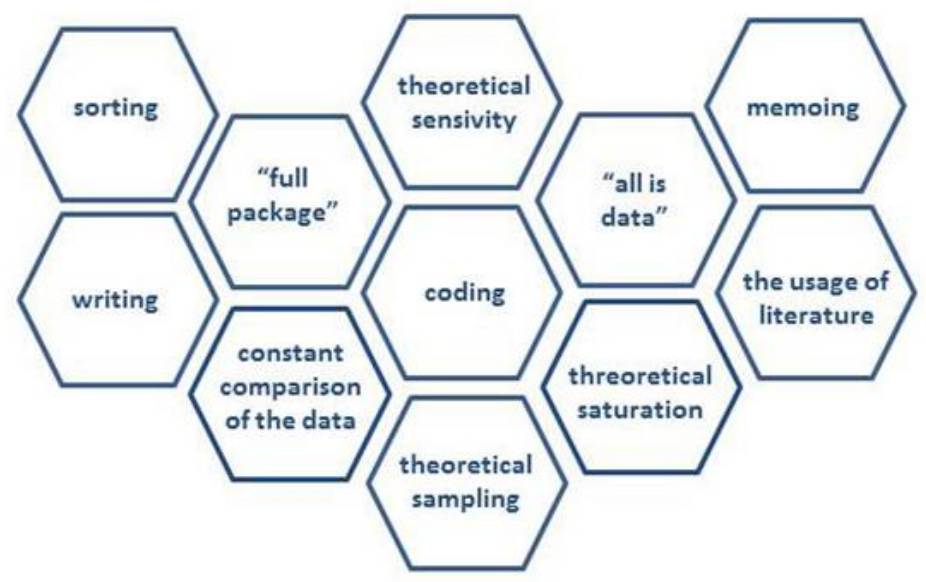

Figure 2. The most important principles of classic GT

The principles of classic GT (fig. 2), such as: "full package", "all is data", coding, constant comparison of the data, theoretical sampling, theoretical sensivity, threoretical saturation, the usage of literature, memoing, sorting, writing, - have shown the systematic way of classic GT thinking. What are the criteria evaluate the credibility of grounded theory? On the menu of research methodology, Holton (2007) notices, classic GT is "table d'hote", not "a la carte". Breckenridge (2010) reminds, that criteria evaluate the credibility of a grounded theory are based upon the fit, work, relevance and modifiability of the theoretical product too. So the set of evaluation of a grounded theory in the context of "procedural credibility" (Elliott, Lazenbatt, 2005; Breckenridge, 2010) is a "full package" (Holton, 2009) evaluation. It is also perceived by Breckenbridge (2010), who points out, that GT enables the generation of a substantive theory that is directly applicable within the substantive area from which it was derived. Moreover, Breckenridge (2010) notices, the emergent grounded theory will also possess a conceptual generality; in a process of moving back and forth between empirical data and theoretical analysis to develop relationships between concepts, GT analysis results in the development of a conceptual theoretical framework that is abstract of specific people, places and times.

Summing up presented GT methodology, it can be said as Christiansen (2017) points out, that GT perspective is about a methodology for discovering and generating theory directly from data instead of logically deriving theory from presupposed premises and subsequent testing/verifying of hypotheses. So presented evolution of GT development and classic GT strategy allows to discuss the idea to use GT for such a dynamic phenomenon research as social innovations for rural development are in nowadays.

\section{DISCUSSION AND CONCLUSIONS}

Discussing the idea to use presented GT methodology in the context of social innovations for rural development research, the insights of recent researchers (Bosworth et al. 2015, 2016; Melece, 2015; Bock, 2016; Copus et al. 2017, Frias-Navarro et al. 2016; Katonáné Kovács et al. 2016; Backhaus et al. 2017; Neumeier, 2017) are taken to advantage. According to Melece (2015) nowadays, social innovations, particularly in the rural areas, focus on successful solution of different social, economic, political and environmental issues. Social innovation is seen as a promising solution to gaps deepened as a result of austerity politics (Edwards-Schlachter et al. 2011; TEPSIE, 2014; Bock, 2016, as cited in Neumeier, 2017). It is also perceived by Copus et al. (2017), that not all local contexts are capable of nurturing social innovation. Social innovations are defined as "targeted new combination or new configuration of social practices" (Howaldt, Kopp and Schwarz 2015, p. 36, as cited in Domanski, Kaletka, 2017). Within the concept of "social innovation" different aspects have been addressed that draw on different strands and merely blur the essence of the concept rather than clarifying it (Dro, Therace 2011, p. 102; Brackertz, 2011, p. 1; Borzaga, Bodini, 2012, as cited in Neumeier, 2017). As social innovation is a "contested concept" (Bock, 2016, p. 2, as cited in Copus et al. 2017), it is interesting to point out, that the context of social innovations for rural development is becoming more and more fluid: it is noticed that social innovation does not have fixed boundaries (Copus et al. (2017). The role, that social innovation plays, as Bock (2016, as cited in Copus et al. 2017, p.13) points out, "shifts our perspective from fixed actors in separate rural areas towards a more fluid image of shifting actors and relations and functional networks operating across places and beyond the local and rural". Katonáné Kovács et al. (2016) points out, that the biggest threats to successful social innovations in rural regions are: the lack of initiators and the lack of supporting context that is commitment/involvement of active local actors. According to Bosworth et al. (2015) the "burgeoning literature on social innovation is replete with references to the need for a sound conceptual or methodological framework, greater clarity and more theoretical and empirical work". Thus, Bosworth et al. (2016) point out, rather than translating broader policy to "fit" into a locality, emphasizing the local setting allows alternative 
approaches to deliver potentially radically different solutions. According to Frias-Navarro et al. (2016), the regional knowledge creation is relevant because of the changing conditions in a turbulent environment where it becomes necessary to innovate constantly, so even "engineers should be encouraged to use qualitative research methodologies as tools for deep understanding the problems to subsequently proceed to raise quantitative research that can complement their process.

As argued by Bosworth et al. (2015), innovation is essentially about using creativity and new combinations of resources to generate value and further in-depth research (Neumeier, 2017) focusing on social innovation is needed. If we want "to understand the sources of innovation we need to understand the milieu in which creativity takes part" (Pol and Ville, 2009, p. 884, as cited in Backhaus et al, 2017). So Nicholls et al. (2015) point out, that social innovation offers an exciting space for research and debate. GT methodology could be one of the methodologies, which could be used in this scientific debate. According to Goulding (2017), GT is used as a methodology to develop new theoretical insights, build alternative frameworks, and challenge the doxa of established conventional wisdom. So GT as a general methodology that can be used across the social sciences in areas that involve human, often social, behavior. Charmaz (2016) thinks that GT is cutting across so many areas (forestry, civil engineering, architecture). Corley (2016) notices, as an avid user of grounded theory methods and techniques for most of his scholarly career, he has found the approach extremely useful in studying organizational phenomena, especially those involving change and believes them to be some of the best approaches for gaining insight into the complexities and intricacies of the modern organization. According to him, GT approaches to organizational research have proven to be some of the most powerful forms of inquiry we have into modern organizing and organizations. In a rural context, Bosworth et al. (2016) point out, the drivers of social change can be both internal and external making the interfaces between local and extralocal and topdown and bottom-up influences especially pertinent to the emergence of social innovations. As it was mentioned, that GT is an act of conceptual abstraction, so careful usage of the main principles of classic GT, such as: "full package", "all is data", coding, constant comparison of the data, theoretical sampling, theoretical sensivity, threoretical saturation, the usage of literature, memoing, sorting, writing, - the systematic way of classic GT thinking - could led to find new and important insights and „emerge“ the patterns of social innovations in rural development research area.

So it is meaningful to conclude with rhetorical question: How should social innovation for rural development be researched? As GT is the methodology, which provides the possibility to researcher to look at the phenomenon from inside without formulating the hypothesis, i.e., to "emerge" the theory, hopefully GT could be the paradigm that would help researchers discover new insights and develop new theories, explaining the processes of social innovations for rural development.

\section{REFERENCES}

1. Arora, E. 2016. Joy and Laughter in the Therapy Room: A Grounded Theory Study. Middlesex University and Metanoia Institute, $\mathrm{PhD}$ thesis

2. Backhaus, J., Genus, A., Lorek, S., Vadovics, E., Wittmayer, J.M. 2017. Social Innovation and Sustainable Consumption: Research and Action for Societal Transformation. Routledge.

3. Bosworth, G., Rizzo, F., Marquardt, D., Strijker, D., Haartsen, T.,Thuesen, A. 2015. Identifying Social Innovations in Local Rural Development Initiatives. Paper presented at the European Society for Rural Sociology Congress, Aberdeen.

4. Bosworth, G., Rizzo, F., Marquardt, D., Strijker, D., Haartsen, T., Thuesen, A. 2016. Identifying social innovations in European local rural development initiatives, Innovation: The European Journal of Social Science Research, pp. $442-446$. https://doi.org/10.1080/13511610.2016.1176555

5. Breckenridge, J. 2009. Demystifying Theoretical Sampling in Grounded theory Research. The Grounded Theory Review, Vol. 8, No. 2, pp. 113-126

6. Breckenridge, J. 2010. Being Person Driven in a Service Driven Organisation: A Grounded Theory of Revisioning Service Ideals and Client Realities. $\mathrm{PhD}$ thesis

7. Bryant, A. 2017. Grounded Theory and Grounded Theorizing. Pragmatism in research practice. Oxford University Press. https://doi.org/10.1093/acprof:oso/9780199922604.001.0001

8. Carrero, V. Peiró, J.M., Salanova, M. 2000. Studying radical organizational innovation through grounded theory. European journal of work and organizational psychology, Vol. 9 (4), pp. 489-514. https://doi.org/10.1080/13594320050203102

9. Charmaz, K., Keller, R. 2016. A Personal Journey with Grounded Theory Methodology.Kathy Charmaz in Conversation With Reiner Keller [60 paragraphs]. Forum QualitativeSozialforschung/Forum: Qualitative Social Research, Vol. 17(1), Art. 16.

10. Christmann, G. B. 2016. Analysing Changes in Discursive Constructions of Rural Areas in the Context of Demographic Change. Towards Counterpoints in the Dominant Discourse on "Dying Villages". Comparative Population Studies, Vol. 41, pp. 359-378

11. Christiansen, O. 2017. Replacing The Discovery of Grounded Theory. The Grounded Theory Review, Vol.16, Iss.1,

12. Corley, K.G. 2015. A Commentary on "What Grounded Theory Is...": Engaging a Phenomenon from the Perspective of Those Living it. Organizational Research Methods, SAGE, Vol. 18(4), pp. 600-605. https://doi.org/10.1177/1094428115574747

13. Collins, J. 2011. New Normalizing: a Grounded Theory of the transition for migrant health care professionals. PhD thesis. Dublin City University

14. Copus, A., Perjo, L., Berlina, A., Jungsberg, L., Randall, L., Sigurjónsdóttir, H. 2017. Social innovation in local development: Lessons from the Nordic countries and Scotland. NORDREGIO working paper

15. Domanski, D. Kaletka, C. 2017. Exploring the Research Landscape of Social Innovation - A deliverable of the project Social Innovation Community (SIC). Dortmund: Sozialforschungsstelle.

16. Elliott, N., Lazenbatt, A. 2005. How to recognise a "quality" grounded theory research study. Australian Journal of Advanced Nursing, Vol. 22(3), pp. 48-52 
17. Galliano, D., Gonçalves, A., Triboulet, P. 2017. Eco-Innovations in Rural Territories: Organizational Dynamics and Resource Mobilization in Low Density Areas. Journal of Innovation Economics \& Management, Vol. 3 (24), pp. 35-62

18. Glaser, B.G., Strauss, A.L. 1967. Discovery of grounded theory: Strategies for qualitative research. Hawthorne. NY: Aldine de Gruyter

19. Glaser, B.G. 1978. Theoretical Sensitivity. Advances in the Methodology of Grounded Theory. Mill Valley: Sociology Press

20. Glaser, B.G., Holton, J. 2004. Remodelling Grounded Theory. Forum: Qualitative Social Research, Vol. 5, (2), pp. 1-17

21. Glaser, B.G. 1992. Emergence vs. Forcing: Basis of grounded theory analysis. Mill Valley, CA: Sociology Press

22. Glaser, B.G. 2009. Theoretical writing. The Grounded Theory review, No. 3, Vol. 08

23. Glaser, B.G. 2010. The future of GT. The Grounded Theory review, Vol. 9, No. 2, pp. 1-14

24. Goulding, Ch. 2017. Navigating the Complexities of Grounded Theory Research in Advertising. Journal of Advertising, Vol. 46(1), pp. 61-70. https://doi.org/10.1080/00913367.2017.1281775

25. Joshi, R.G. 2015. The essence of lived experiences of grassroots innovators a phenomenological study. The University of Technology Sydney, Faculty of Business, PHD thesis

26. Frias-Navarro, R., Montoya-Restrepo, L.A. 2016. Methodological approach using grounded theory in industrial engineering research applied to a study of a regional knowledge creation process. WIETE, Vol.18, Num.1

27. Hesam, M., Rezvani, M.R. 2017. Recognition and Analysis of Network Relations in Rural Tourism Through Grounded Theory: A Case Study on Mountainous Valley Route of Haraz, Iran. Journal of Sustainable Rural Development, Vol. 1(1), pp. 39-52. https://doi.org/10.18869/nrip.jsrd.1.1.37

28. Hernandez, Ch. A. 2009. Theoretical coding in grounded theory methodology. The Grounded Theory Review, No.3, Vol. 08

29. Holton, J.A. 2007. Coding Process and its Challenges. The Sage Handbook of Grounded Theory. Ed. A. Bryant, K. Charmaz. Thousand Oaks: Sage Publication, pp. 265-289. https://doi.org/10.4135/9781848607941.n13

30. Holton, J.A. 2009. Qualitative tussles in undertaking a grounded theory study. The Grounded Theory Review, Vol. 8, No. 3, pp. 37-49

31. Holton, J.A., Walsh, I. 2016. Classic Grounded Theory: Applications With Qualitative and Quantitative Data. Sage Publications.

32. Holton, J.A. 2017. The Discovery Power of Staying Open. The Grounded Theory Review, Vol. 16, Iss. 1

33. Hennon, Ch.B. 2012. Entrepreneurship, Farming, and Identity: A Phenomenological Inquiry. Entrepreneurship - Gender, Geographies and Social Context, Prof. Thierry Burger-Helmchen (Ed.), InTech

34. Katonáné Kovács, J., Varga, E., Nemes, G. 2016. Understanding the process of social innovation in rural regions: some Hungarian case studies. Studies in Agricultural Economics, Vol. 118 pp. 22-29. https://doi.org/10.7896/j.1604

35. Kenny, M., Fourie, R. 2014. Tracing the history of grounded theory methodology: From formation to fragmentation. The Qualitative Report, Vol. 19(103), pp. 1-9.

36. Konstantos, H., Siatitsa, D., Vaiou, D. 2013. Qualitative approaches for the study of Socially Innovative Initiatives. In F. Moulaert, F. Moulaert, et al.(Eds.), The international handbook on social innovation: Collective action, social learning and transdisciplinary research (pp. 274-284). Northampton,MA: Edward Elgar Pub. https://doi.org/10.4337/9781849809993.00036

37. Melece, L. 2015. Social innovation and its types in rural areas. Proceedings of the 2015 international conference "Economic science for rural development" Jelgava, LLU ESAF, 23-24 April 2015, pp. 142-153.

38. Muller, M. 2010. Grounded theory methods. Presentation at HCIC 2010, Winter Park, CO, USA, February 2010.

39. Neumeier, S. 2017. Social innovation in rural development: identifying the key factors of success. The Geographical Journal, Vol. 183, Iss. 1, pp. 34-46. https://doi.org/10.1111/geoj.12180

40. Nicholls, A., Simon, J., Gabriel, M., Whelan, Ch. 2015. New Frontiers in Social Innovation Research. Palgrave Macmillan, https://doi.org/10.1057/9781137506801

41. Ross, A.J. 2014. Working in rural areas - the experiences of Umthombo Youth Development Foundation graduates. Afr J Prm Health Care Fam Med. 6(1), Art. 673, 7 p. http://dx.doi.org/10.4102/phcfm. v6i1.673

42. Rupšienè, L., Pranskūnienè, R. 2010. The Variety of Grounded Theory: Different Versions of the Same Method or Different Methods? Socialiniai mokslai, Nr. 4(70), pp. 7-19.

43. Scott, H. 2017. Growing Grounded Theory: Doing my Bit. The Grounded Theory Review, Vol. 16, Iss. 1

44. Takala, T., Hujala,T., Tanskanen, M., Tikkanen, J. 2017. The order of forest owners' discourses: Hegemonic and marginalised truths about the forest and forest ownership. Journal of Rural Studies,Vol. 55, pp. 33-44. https://doi.org/10.1016/j.jrurstud.2017.07.009

45. Tikhonravova, K. 2017. Essentials, Accidents, and "Book-Trailers": A Pragmatic Review of Grounded Theory and Grounded Theorizing: Pragmatism in Research Practice. The Qualitative Report, 22(10), pp. 2764-2771.

46. Walsh. I., Holton, J.A, Bailyn. L., Fernandez, W., Levina, N., Glaser, B. 2015. What Grounded Theory Is... A Critically Reflective Conversation Among Scholars. Organizational Research Methods, Vol. 18(4), pp. 581-599. https://doi.org/10.1177/1094428114565028 